\title{
Integrating constructive feedback in personalised e-learning
}

Article

Accepted Version

Lubega, J. and Williams, S. (2009) Integrating constructive feedback in personalised e-learning. Lecture Notes in Computer Science (5685). pp. 218-229. ISSN 0302-9743 doi: https://doi.org/10.1007/978-3-642-03697-2_21 Available at https://centaur.reading.ac.uk/14770/

It is advisable to refer to the publisher's version if you intend to cite from the work. See Guidance on citing.

Published version at: http://rd.springer.com/chapter/10.1007/978-3-642-03697-2_21\#

To link to this article DOI: http://dx.doi.org/10.1007/978-3-642-03697-2_21

Publisher: Springer

All outputs in CentAUR are protected by Intellectual Property Rights law, including copyright law. Copyright and IPR is retained by the creators or other copyright holders. Terms and conditions for use of this material are defined in the End User Agreement.

\section{www.reading.ac.uk/centaur}

\section{CentAUR}

Central Archive at the University of Reading

Reading's research outputs online 


\title{
Integrating Constructive Feedback in Personalised E-learning
}

\author{
Jude .T. Lubega [jlubeg@cit.mak.ac.ug] \\ Makerere University, Faculty of Computing and Information Technology, \\ P.O. Box 7062, Kampala, Uganda, East Africa \\ Shirley Williams [shirley.williams@ reading.ac.uk] \\ Department of Computer Science, University of Reading, P.O. Box 225, \\ Whiteknights, READING, Berkshire, RG6 6AY, UNITED KINGDOM
}

When using e-learning material some students progress readily, others have difficulties. In a traditional classroom the teacher would identify those with difficulties and direct them to additional resources. This support is not easily available within e-learning.

A new approach to providing constructive feedback is developed that will enable an elearning system to identify areas of weakness and provide guidance on further study. The approach is based on the tagging of learning material with appropriate keywords that indicate the contents. Thus if a student performs poorly on an assessment on topic X, there is a need to suggest further study of $\mathrm{X}$ and participation in activities related to $\mathrm{X}$ such as forums.

As well as supporting the learner this type of constructive feedback can also inform other stakeholders. For example a tutor can monitor the progress of a cohort; an instructional designer can monitor the quality of learning objects in facilitating the appropriate knowledge across many learners.

Keywords and Phrases: E-Learning, Tracking, Constructive Feedback, LMS, Personalisation, Knowledge Construction

\section{INTRODUCTION}

The internet has created possibilities for transferring, sharing and reusing content. The increasing adoptation of the internet use in higher education learning demonstrates its potential as a future learning medium. Educational providers are exploring the effective use of e-learning by incorporating it in their teaching. There are several factors that have influenced educational providers to incorporate Learning Management Systems (LMS) within teaching. These factors include the rapid increasing number of students, the need for learning and the need to prepare students to suit the knowledge economy [Harasim, 2000]. The use of LMS has created better opportunities for learners to learn ubiquitously. The LMS are capable of creating, fostering, delivering, tracking and facilitating learning more effectively. However these learning tools have not yet fully realised the potential of learning standards [SCORM, 2003; IEEE, 2003 and IMS, 2003] and technology by supporting stakeholders with constructive real-time feedback. The lack of direct and immediate contact between the learner and tutor poses a threat to the quality of e-learning [Hill, 2002)]. The teacher in a class setting is provided with a variety of opportunities for 
interacting and supporting learners. One of the key roles of the teacher is to support learners with constructive feedback during learning. The learners are able to reflect and improve on their knowledge construction. The difficulty with LMS to provide constructive feedback during e-learning has encouraged researchers to devise other effective methods.

The current LMS have been further developed to incorporate technologies such as reusable learning objects (RLO) [Wiley, 2000]. These RLO enable instructional designers to configure content to suit individual learners and allow effective tracking where constructive feedback can be integrated. Reusable Learning Objects have created better opportunities in the content instruction which allows personalisation of content. Learners can request for this personalised content which is dependent on their learning styles [Keefe, 1979]. Learning styles are methods, through which learners perceive, interpret and processes information [Bergeron et. al., 2003]. Jung [1923] asserts that learners process information in different ways which is dependent on their learning styles. For example a learner can request for content that is presented in a step-by-step sequential manner or in a random manner. The example describes how information is presented to the judger and perceiver respectively. Interactions with such personalised content present a true learning path for the learners. The tracked learning path contains information about the learner's interactions from which constructive feedback can be offered to the stakeholders.

The main focus of this paper is to describe how constructive feedback can be integrated within e-learning to support stakeholders. The constructive feedback depends on the tracked information from individual interactions with the learning activities. The feedback depends on specific learning activities such assessment which measures the attainment of learning objectives. Therefore it is essential to capture individual learning path if such constructive feedback is to be offered. LMS can be modified to integrate this form of feedback which can greatly improve the learning experience.

\section{E-LEARNING PROCESS}

E-learning is a process of knowledge construction that involves stakeholders participating in several online activities such as content authoring, assessment and collaboration. They participate in the different activities so that they can achieve their learning goals. As Constructivism states, learners play an active role and take on responsibility to construct their own knowledge and meaning [Fosnot, 1996; Steffe \& Gale, 1995; Honebein et al., 1993]. This active role is clearly witnessed in e-learning environments which are designed to offer personalised learning process. A personalised learning process is one where learners use LMS to interact with learning content designed to suit their own learning styles with the aim of achieving new knowledge. These LMS are currently trying to cope with the paradigm shift from teacher-centred to learner-centred. In learnercentred learning, learners construct knowledge through inquiry, communication and creative thinking. They use different learning styles to make their own judgement hence making meaning out of the learning process. The different ways by which information is presented to the learners affects how they act on it. The individual learner's actions become the basis of what feedback should be generated for them. 
The seven principles of good practice [Chickering and Gamson, 1987] act as a benchmark for guiding e-learning. These seven principles emphasise:

- encouraging contacts between students and teacher

- encouraging cooperation among students

- encouraging active learning

- offering prompt feedback

- emphasising time on tasks

- communicating high expectation to the students

- respecting different learning styles during learning

Advancement in technology has encouraged the implementation of the seven principles within e-learning environments. Several functionalities have demonstrated how the principles have been incorporated in LMS such as collaboration tools, personalisation, assessment and feedback. However some of the functionalities have not been thoroughly developed to fit in the new learning paradigm.

The theory of constructivism enables us to identify important features for the learning process. The features that can be identified include personalisation of content to suit the individual learner, tracking the learner's activities at each level of the learning process and generating personalised feedback. The features aim at helping the learners attain their individual learning goals from the learning process. The learning goals are determined by both the educational and personal learning requirements. The educational learning requirements are based on the Learning Object (LO) concept [Cisco, 2003] which represents the learning content. Wiley [2000] defines a LO as any digital resource that can be reused to support learning. The LO has created a big impact on how learning content is stored, delivered, used and managed. The LO can be easily reused and configured for personal use.

During the e-learning process, the learners aim at achieving the set learning objectives. These learning objectives are set by the educational providers and their attainment measured by assessment. Tracking interactions with the assessment learning activity helps to monitor the student's progress, control the pace of learning and evaluate the teaching strategy. During the learning process learners need to know what they can do to improve hence require constant feedback. The learning content should be designed to reflect the objectives to be attained at each learning level. The instructional model for constructivist learning [Sun and Williams, 2004] separates the content into chucks at different levels. The content levels include LO, Information Object (IO), practical and assessment level see figure 1. Each level denotes the expertise the learner can attain at the end of the learning process. The learning levels are turning points for the learning process as they determine what happens at the next level. Personalised tracking [Lubega et. al., 2005] capable of monitoring the learning path at each learning level determines what feedback can be generated for stakeholders.

The Overview contains general information about the module, such as the level, learning objectives, pre-requisites, co-requisites, learning outcomes and credits. Metadata is used 
to describe the objectives for the different objects within the LO. The Information Object contains the core content and represents a topic within the module, e.g., Building your Database in the SQL module. Within the IO we have a Practical Object and Assessment Object. The Practical Object is used to determine the learner's practical skills on the topic. The Assessment Object found at both LO and IO determines the learner's performance; this is used for generating feedback about the learning process. The Summary contains a review of the module, which assists students in self-assessment and self-reflection through recommendations.

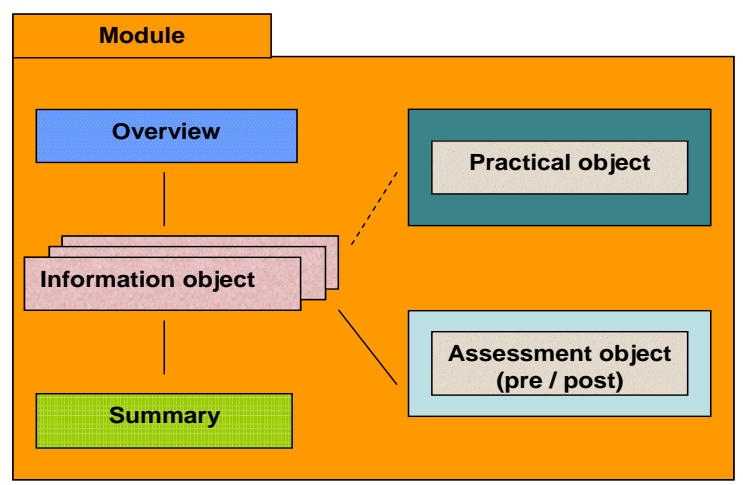

Figure 1.Template for module package

\section{ASSESSMENT}

Assessment refers to the activities undertaken by both students and teachers to diagnose learning problems hence improving learning and teaching. Assessment enables students to fully understand how far they have achieved their learning goals through effective feedback [Elwood and Klendowski, 2002]. Assessment can be carried out in several forms and for several purposes. However there are two common types of assessments used to diagnose learning problems within e-learning. The summative assessment is used as evidence of accountability on deciding if the learning was effective [Stigins, 2002]. It is used for grading or ranking student performance hence informing them of their overall achievement. Formative assessment is one that is carried out in series during the learning process aiming at providing constructive feedback to the learners [Torrance and Pryor, 1998]. These two assessment types are usually designed electronically in form of multiple choice questions where learners select one answer from the list of answers offered per question. The multiple choice questions are linked to the learning objectives within the LO and IO. The summative assessment measures the attainment of the learning objective at the LO level and formative at the IO. Sun and Fu [2005] describe an assessment object model that can be used in higher education to measure achievement attained during the learning process, see figure 2 .

Wiggins [1998] notes that the nature of assessment influences what is learned and the degree of meaningful engagement carried out by students in the learning process. An assessment that is authentic and contains feedback can be used to improve the knowledge construction than one without feedback. Continuous assessment helps tutors trace the learner's progress and also determine the impact of the content to the learning process. The assessment indicates to the learners their weaknesses, assistance required for 
improving and progress made during the knowledge construction process. Having only grades on the assessment has little effect on the subsequent performance of learners [Crooks, 1988]. This is because this type of feedback in form of grades never mentions which area the student should improve hence does not lead to self-reflection.

\begin{tabular}{|c|}
\hline AssessmentObject \\
\hline Title \\
\hline Assessment Type \\
\hline Question Type \\
\hline $\begin{array}{c}\text { Number of } \\
\text { Questions }\end{array}$ \\
\hline Duration \\
\hline Instructions \\
\hline $\begin{array}{c}\text { Requirement for a } \\
\text { Pass }\end{array}$ \\
\hline $\begin{array}{c}\text { Number of } \\
\text { Attempts }\end{array}$ \\
\hline Questions \\
\hline Result \\
\hline
\end{tabular}

Figure 2: An Assessment Object Model

\section{FEEDBACK}

Feedback may be described as any communication or procedure offered to the stakeholder in response to the accuracy of their actions. Feedback is an important component between the learners and tutors during a learning process. Learners get feedback from their tutors to improve on their learning process. Feedback has a significant impact on the learning process since it adds value that results in improving quality and success in a course. Feedback is important to the tutors in that it reflects how best the student gained in the learning process. It is particularly emphasised by the learning theories [Duffy and Cunningham, 1996] that feedback is the important instrument used in a learning process where progress, improvements and achievements are provided in real-time. In e-learning feedback is aimed at providing information about the learning process and the mastery of the learning goals especially in circumstances where there is no direct contact between learner and tutor. Feedback that provides information to reflect on the effectiveness of strategies taken during learning needs to be provided within LMS. Such feedback demonstrates to the stakeholders that there is always support for improvements in the absence of tutors. Successful feedback [Kluger and De Nisi, 1996] focuses on the task, its objectives and the learner attention is directed to objectives. The learners always seek information related to their past action from expert sources such as tutors and forums for improvements.

It has been noted by Mory [2003] that there has been frequent lack of feedback electronically generated by e-learning environments. There is less contextual, constructive and expert mediated feedback within LMS. In the face to face (F2F) teaching learners can easily receive direct feedback from their teachers in real-time. Within e-learning the learners rely on the LMS to offer the direct support which is difficult to generate especially for personalised learning. Generating personalised feedback during knowledge construction [Lubega et. al., 2005] has great potential in improving e-learning. The personalised learning path is monitored and the information 
used in the generation of the personalised feedback in real-time. Current approaches taken in offering feedback within LMS do not allow learners to explore the content areas where they seem to be weak. The feedback is less constructive and usually questionanswer related. The learners need to explore the content areas where they are weak before they can proceed to the next learning level. Non-specific feedback is deemed to be useless to the learners [Rowntree, 1987] as they progress with their knowledge construction. Feedback should be generated on timely basis when it is more relevant [Gipps, 1994] if immediate improvements are needed.

With the increasing number of learners, techniques are sought to support them during their knowledge construction. Forums have shown that they are capable of supporting learners with effective feedback. Learners can freely visit the forums of their specified topic; ask questions or read answers related to their topic. Learners usually find answers which they can use to solve existing problems hence improving their knowledge construction process. Feedback that can automatically select useful content links and forums to be used for improvements in relation to the assessment results can be effective for learners. The learners can immediately visit the links and find out why they failed particular questions within the assessment hence gaining more knowledge. This type of facilitation is desirable for future e-learning environments if they are to succumb to the learning paradigm shift to learner-centered.

\section{TRACKING PROCESS}

Tracking functionality is considered to be very important because it generates the information from which feedback is offered. Tracking in relation to e-learning is the monitoring of learner interactions with learning activities during knowledge construction. The typical tracking information within LMS include: log files, duration of visit, learning unit visited by learner/time/frequency, collaborations and assessment. However not all traced information is currently used in improving knowledge construction. Some researchers have put to use tracked information from LMS in improving knowledge construction [Lubega and Williams, 2004; Lubega and Williams, 2006]. They have shown that tracked information can be used to detect weak learners, laggards and effects of particular learning activities such collaboration to e-learning.

Tracking is on the increase within web applications and the aim is to learn more about users so that they can be served more effectively. It has been applied within e-learning in different scenarios such as detecting drifting users and adapting learners to past learning habits [Grabtree and Soltysiak, 1998; Koychev and Schwab 2000]. The tracking process currently used in many of the LMS does not favour offering of constructive feedback to stakeholders. It does not also monitor individual interactions with learning activities but concentrate on monitoring how the available content has been accessed. Lubega et. al. [2005] describe how personalised learning activities can be monitored and the information used for offering feedback. The feedback offered is dependent on the analysed monitored information and predefined feedback templates. The analysed information is related to both the individual and group of learners. The feedback generated from the individual information is meant for the learner and tutor. Feedback generated from the group monitored information is for the tutor and instructional designer. 
Although this method for personalised tracking aims at offering personalised feedback in real-time to the stakeholders, there is a need to offer a feedback that highlights weak areas. It is important to integrate constructive feedback that highlights content areas of weakness, suggest links to the weak content areas and useful forums. The forums can be designated by the tutors based on topics, key words and so on. The mechanism for generating such feedback requires a well planned and designed content that has the LO, IO, assessment objects linked to each other.

\section{INTEGRATING CONSTRUCTIVE FEEDBACK IN LMS}

Constructive feedback refers to the support offered to learners during learning and contains useful content links that can be used for improvements. For example constructive feedback offered to the learner after taking the assessment can include:

\footnotetext{
"You have successfully attained $60 \%$ of the learning objectives for this topic. You attempted 2 application and 4 theoretical questions correctly. However for a better achievement of the learning objectives, you need to consider reading the following content; Content One, Content Two and Content Three. You can also visit the following Forum to help you improve on your practical work."
}

This advanced level of constructive feedback can be challenging to generate for stakeholders within LMS. Creating content in form of LO and linking the learning objectives to the assessment questions provides an easy mechanism on how to generate this feedback. Figure 3 describes a module containing three learning objectives interlinked to individual Information Objects. Each Information Object contains learning objectives which are interlinked to assessment questions within the assessment object. For example Information Object one contains learning objectives $\operatorname{LObj}_{11}, \operatorname{LObj}_{12}, \operatorname{LObj}_{13}$. The assessment object contains questions that are designed to assess the attainment of the specific learning objective. The questions are designed to assess both theoretical (A) and application (P) understanding. For example Q1 in assessment object one is used to assess the attainment of learning objective one $\left(\operatorname{LObj}_{11}\right)$. 


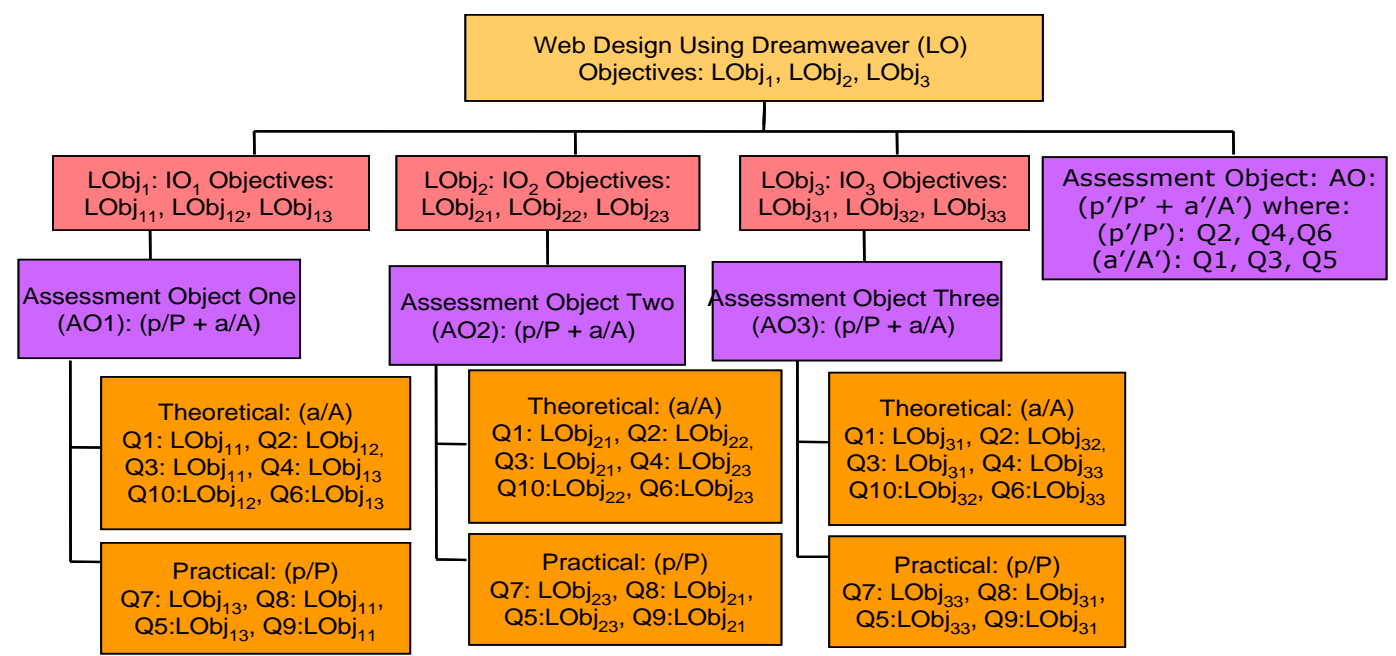

Figure 3. An Example of a Module with interlinked objects

If the learning content is instructionally designed as shown in figure 3, results from the assessment can be easily transformed into constructive feedback. The main aim of assessment as described in section 2 is to measure attainment of learning objectives. Any questions answered incorrectly may reflect failure to attain a specified learning objective. Analysing the assessment results by sorting out the correct and incorrect questions will indicate what questions require feedback hence linking them to appropriate content.

The mechanism for integrating constructive feedback within knowledge construction contains four main components used in the process.

1. Content Component

2. Assessment Analysis Component

3. Search Engine Component

4. Feedback Generation Component

The figure 4 describes a model for the mechanism that integrates constructive feedback in e-learning by interlinking the different components. 


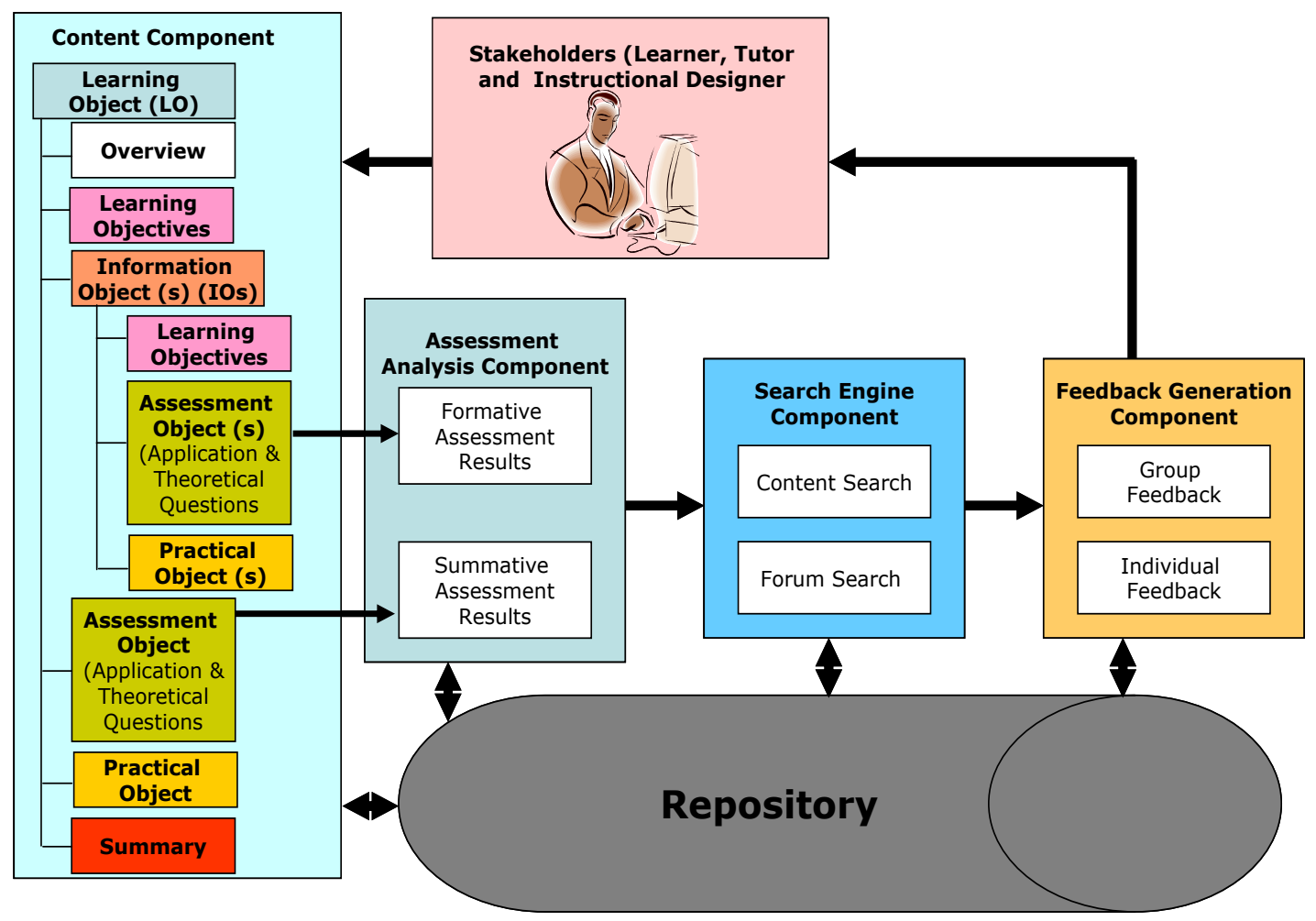

Figure 4 Model Describing how to Integrate Constructive Feedback

\subsection{Content Component}

This is a component where the content design is configured to suit the feedback generation process. The content in form of LO is configured as described in figure 3 so that the objects are interlinked. The content topics, assessment questions and key words are linked to learning objectives. Anchors are used to locate content areas related to learning objective and allow easy search for specific content. On a single content page you can have more than one anchor to locate specific content. Figure 5 describes a module containing three topics with anchors on them. The module and topics can easily be searched within the repository by use of unique anchors placed on them. In this illustration the anchors used are $\mathrm{LObj}_{1}, \mathrm{LObj}_{11}, \mathrm{LObj}_{12}$ and $\mathrm{LObj}_{13}$ linked to the module and topics titles respectively. Therefore if the feedback required for improvement is related to anchor LObj ${ }_{11}$, all content identified by that anchor will be retrieved and offered as content links within the constructive feedback 
$<\mathrm{h} 4>1$. Understanding Dreamweaver interface, tools and palettes $<\mathrm{a}$

name $="$ LObj $_{1} "></$ a $></$ h4 $>$

$<\operatorname{tr}>$

$<$ td colspan="2" $><$ font size="2">1.1. $<$ font face="Times New Roman, Times, serif" $><a$

href="Document Window.htm" $>$ Document window $</ a><$ font $></$ font $><$ a

name $=" \operatorname{LObj}_{11} "></ \mathrm{a}><\mathrm{br}>$

$<$ font size="2" $>1.2$. $<$ font face="Times New Roman, Times, serif" $><$ a href="Pallets and

Inspectors.htm" $>$ Dreamweaver palettes and inspectors $</ \mathrm{a}></$ font $></$ font $><\mathrm{a}$

name $=" \operatorname{LObj}_{12}$ " $></ \mathrm{a}><\mathrm{br}>$

$<$ font size="2" $>1.3$. $<$ font face="Times New Roman, Times, serif" $><$ a href="View

options.htm" $>$ Dreamweaver view options $</ \mathrm{a}><\mathrm{a}$ name $=$ "LObj ${ }_{13}$ " $></ \mathrm{a}></$ font $></$ font $></$ td $>$ $</$ tr $>$

Figure 5. Module and Topics mapped with anchors

The content body and assessment questions are also tagged with anchors related to the specific learning objectives as illustrated in figure 5. Forums can be created and named after key words such as "palettes" and anchors placed on them. It is the anchors that are used to locate the appropriate content and forums that are suggested within the feedback. When the content is properly configured and pre-planned, it is stored within the repository where it can be searched and reused during knowledge construction.

\subsection{Assessment Analysis Component}

This component is responsible for analysing the assessment results in different forms. It computes the results for the different types of questions (theoretical and application) and the overall results. The analysis is carried out for both the summative and formative assessments at the different learning levels. Once the assessment questions in form of multiple choices have been attempted by the learners, the correct and wrong questions are determined. The correct and wrong questions results are used to determine pass/fail rate which is incorporated within the feedback.

Sorting out the wrongly answered questions from the correct one is carried out in this component using various algorithms. There are several algorithms that can be used for the assessment analysis during this personalised tracking process [Lubega et. al., 2005]. The algorithms compute assessment results based on the type of question (theoretical/application), learning level ( $\mathrm{LO} / \mathrm{IO})$ and user (individual/group). The anchors on the wrongly answered questions are determined to be used in locating appropriate content to be offered in the constructive feedback. If there are several anchors relating to the same content, one of them is considered to locate the necessary content. The analysed assessment results are then stored within the repository for future use during feedback generation. The anchors detected for the wrongly answered questions are sent to the search engine so that they can be used to locate the content required for the feedback from the repository.

\subsection{Search Engine Component}

This component aims at searching for content areas that will be offered within the constructive feedback. The search engine depends on the assessment analysis component to find suitable content. If no anchors are sent to the search engine for locating specific 
content, no content links will be included within the feedback. When the anchors are presented to the search engine, a search is carried out within the repository to locate content of interest.

When the content of interest has been found, a link is created on the keywords that were used originally during the tagging with anchors. For example if the anchor $\operatorname{LObj}_{12}$ is searched and content titled "palettes" is found to be related to it, a link to the content is created on the keyword. The linked keyword (palettes) is then dispatched to the feedback generation component. Several linked words and forums may be created depending on the anchors presented to the search engine. These content links are the most important part of the feedback because they provide you with the knowledge on attaining the learning objectives.

\subsection{Feedback Generation Component}

This is the component that is responsible for integrating the assessment analysis results with the selected content links to generate constructive feedback for the stakeholders. Within this component there are several feedback templates that are designed so that results from the assessment analysis and search engine are easily integrated. The feedback templates are predefined by the instructional designers to suit a particular module under study. These feedback templates are stored in the repository and retrieved during the feedback generation process. The criteria for storing the feedback templates depends on the performance results in the type of questions (theoretical/application) and the overall attainment of learning objectives $(0 \%, 10 \%, 20 \% \ldots, 100 \%)$. For example a template selected for an overall performance of $60 \%$ with $20 \%$ in theory and $40 \%$ in application will be different from one selected for the same performance but with $30 \%$ in theory and $30 \%$ in application.

The feedback templates contain dynamic content where assessment analysis and search engine results are automatically integrated to generate the necessary feedback. When the results have been integrated within the feedback templates, feedback is immediately generated and dispatched to the stakeholder. The stakeholders respond to the feedback offered to them by visiting the content areas or forums suggested to them. An example is used to illustrate how the constructive feedback is generated for the learner.

The example illustrates how feedback can be offered to IT Degree students studying EBusiness Module. Initially students are provided with content that has been instructionally designed in form of LO. During the knowledge construction process, the students are allowed to interact with the content using their different learning styles. The module (LO) "Designing Web Sites Using Dreamweaver" contains several topics (IO) as

shown in the figure 6. Each topic contains an assessment that measures attainment of the learning objectives for that topic, see figure 6. 


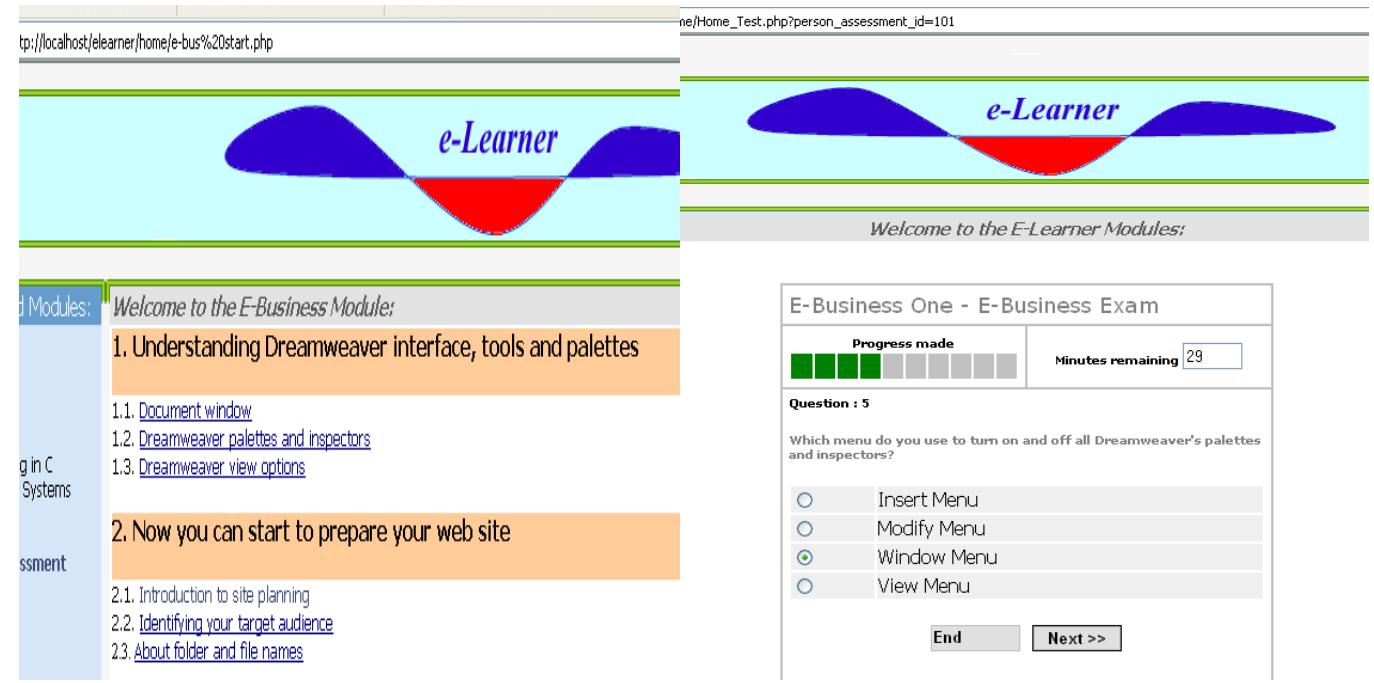

Figure 6. Screen Shots for Content and Assessment for the Module

When the assessment has been taken by the learner, results are automatically computed by the system. The different algorithms within the system compute for the results attained with the theoretical and application questions, determine the questions which are correct and wrong. These analysed assessment results are immediately sent to the search engine component. The wrongly answered questions tagged anchors are then used within the search to locate appropriate content within the repository.

The search results locate content related to "Web Page Templates and Using Timelines" and links created on the keywords. These search results are immediately sent to the feedback generation component. The feedback component generates feedback for the learner containing the content links that were located. The content links are related to the unattained learning objectives content areas. Figure 7 describes an example of the constructive feedback generated for a learner who failed to attain the minimum learning objectives.

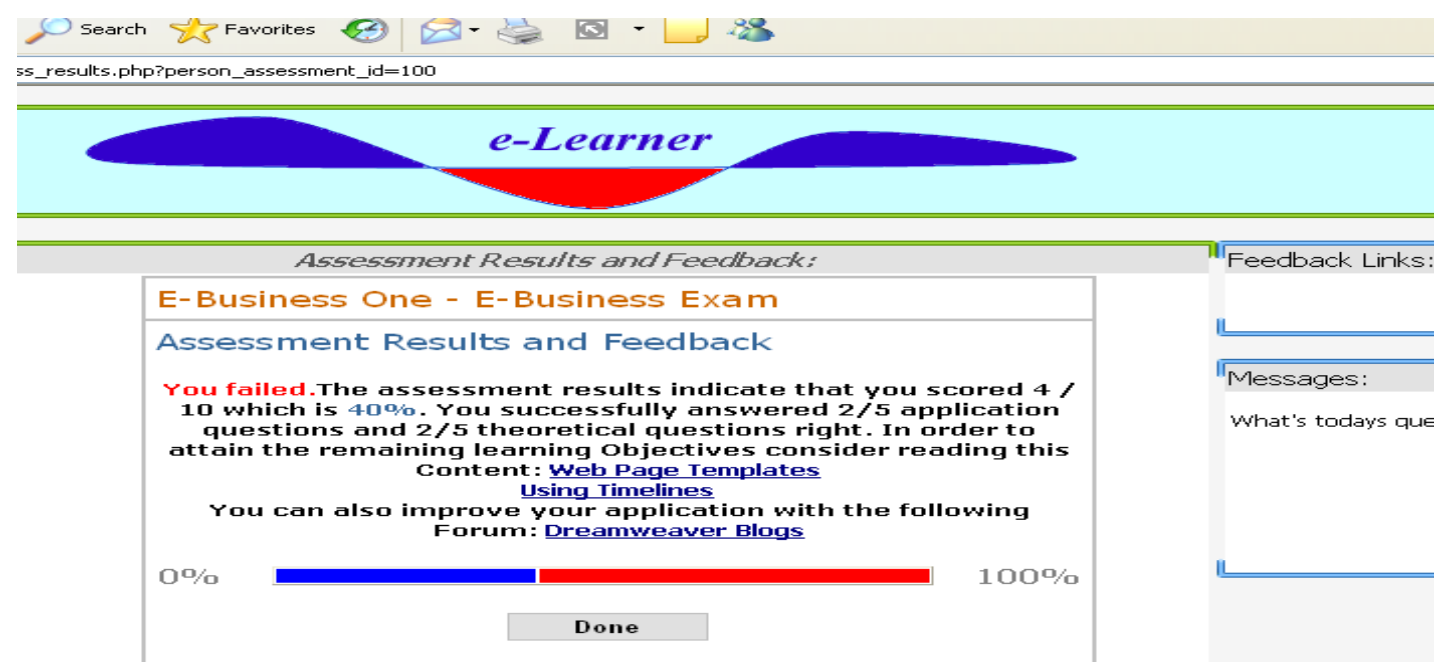

Figure 7. Screen Shot describing a form of Constructive Feedback 


\section{DISCUSSION}

Personalised feedback offered to learners is so vital in transforming their previous knowledge construction process. Such personalised feedback is constructive because it directs learners to their learning weaknesses. This form of feedback has been applied in a Managed Learning Environment (TEMAI) which was used to educate employees of an industrial company [Paiva and Machado, 2002]. The learning environment was designed to support a group of workers in a footwear industry with personalized feedback based on what activities they carried out during learning. The learning environment was built with a synthetic pedagogical agent called Vincent that would offer personalized feedback to the workers during learning. The architecture of TEMAI included a set of micro-learning environments, a trainee model, learning material and Vincent - the pedagogical agent. The work of the agent was to foster the trainees' learning process through motivation as a form of personalized feedback. The agent contained sensors and actors that could establish message-based communication while gathering information about the trainee's performance. Whenever a trainee's performance was not to the desired standards, the agent would send out an emotional feature on the screen either showing, sadness, disappointed, impatient or happy plus a spoken utterance. This form of feedback depended on what activity had been carried out or performance attained by the trainee hence being personalized to their knowledge construction process. It was noted that there was an improvement in the training by use of such personalized feedback.

This form of personalized feedback highlighted the importance of informing learners about their past knowledge construction process. When they are told their weaknesses they are able to adjust on how they learn hence improving the learning process. How the personalized feedback is designed, formulated and delivered may differ but its main purpose should be to enhance the knowledge construction process. The form of personalized feedback proposed in this paper is one that will direct learners to content areas of weakness or discussion areas of importance. These are spotted based on the assessments results which indicate the learning objectives that have not been attained due lack of expertise in a particular content area. Integrating such feedback within e-learning environments can be appreciated by many learners in the new learning paradigm.

\section{CONCLUSION}

This paper focused on the integration of constructive feedback within e-learning in view of offering further support to learners. The provision of constructive feedback needs to be regarded as a priority within LMS under the new learning paradigm (learner-centred). Within the new learning paradigm, learners are demanding for more support during their knowledge construction. Lack of direct interaction with tutors especially in e-learning, creates a big challenge on how to support learners ubiquitously.

The paper has discussed a mechanism that can be used to integrate constructive feedback within LMS. The constructive feedback was based on the analysis of assessment results which measure the attainment of the stipulated learning objectives. The wrongly answered questions indicated the learning objectives that were not attained and required further reading. The anchors placed on the questions were used by the search engine to locate appropriate content to be provided in the constructive feedback. The generated 
feedback described the learner's understanding in both theoretical, application and also provided useful links that can be used for improvements. The links within the feedback lead to the content areas and forum that are related to learning objectives. Such feedback provides the necessary support needed in absence of a tutor and should be encouraged if the quality of e-learning is to be improved.

\section{REFERENCE}

BANGERT, A. W. 2004. The seven principles of good practice: A framework fro evaluating on-line teaching. Internet and Higher Education, 7(3), 217-232.

BERGERON, D. P., ROSEN, D.H., ARNAU, R.C. and MASCARO, N. 2003. Picture Interpretation and Jungian Typology. Journal of Analytical Psychology, 48 (1), 83-99.

CHICKERING, A. W. and GAMSON, Z. F. 1987. Seven Principles for good practice in undergraduate education. AAHE Bulletin, 3-7.

Cisco, 2003. Cisco Reusable Learning Object Strategy: Designing and Developing Learning Objects for Multiple Learning Approaches. Retrieved August 15, 2006 from: http://business.cisco.com/

CROOKS, T. J. 1988. The Impact of Classroom Evaluation Practices on Students, Review of Educational Research, 58, 438-481.

DUFFY, T.M. and CUNNINGHAM, D.J. 1996. Constructivism: Implications for the design and delivery of instruction, in Handbook of research for educational communications and technology, D.H. Jonassen (Ed.), New York: MacMillian Library.

Edu Tools, (2004). E-Learning Tools. Retrieved August 15, 2006 from: http://www.intranetjournal.com/articles/200110/ic_10_17_01a.html

ELWOOD, J. and KLENDOWSKI, V. 2002. Creating of Shared Practice: The Challenges of Assessment Use in Learning and Teaching, Assessment \& Evaluation in Higher Education, 3, 243-256.

FOSNOT, C., 1996. Constructivism: A Psychological theory of learning. In C. Fosnot (Ed.): Constructivism: Theory, perspectives, and practice. New York: Teachers College Press.

GIPPS, C. V. 1994. Beyond Testing: Towards a Theory of Educational Assessment, The Falmer Press, London.

GRABTREE, I. and SOLTYSIAK, S. 1998. Identifying and Tracking Changing Interests, International Journal of Digital Libraries, 2, 38-53.

HARASIM, L. 2000. Shift Happens: Online Education as a new Paradigm in Learning. Internet and Higher Education, 3(1). 
HILL, J. R. 2002. Overcoming obstacles and creating connections: Community building in Web-based learning environments. Journal of Computing in Higher Education, 14(1), 67-86.

HONEBEIN, P.C., Duffy T. and Fishman B., (1993). Constructivism and the Design of Learning Environment: Context and Authentic Activities for Learning, in T.M. Duffy, J. Lowyck and D. Jonassen (eds.), Design Environments for Constructivist Learning, Springer-Verlag, NY, pp. 87-108.

IEEE, (2003). Standard for Learning Object Metadata. Learning Technology Standards Committee. Retrieved August 15, 2006 from: http://grouper.ieee.org/LTSC/wg12/

IMS, (2003). IMS Open Specifications for Interoperable Learning Technology. Retrieved August 15, 2006 from: http://www.imsglobal.org/

JUNG, C.G. 1923. Psychological types or the psychology of individuation. Brace, Harcourt, New York

KEEFE, J. W. 1979. Learning style: An overview. In NASSP's Student learning styles: Diagnosing and prescribing programs Reston, VA: National Association of Secondary School Principals, 1-17.

KLUGER, A. N. and DENISI, A. 1996. The effects of feedback interventions on performance: A historical review, a meta-analysis and preliminary feedback intervention theory. Psychological Bulletin, 119, 2.

KNIPE, D. and LEE, M. (2002). The quality of teaching and learning via videoconferencing. British Journal of Educational Technology, 33(3), 301-311.

KOYCHEV, I. and SCHWAB, I. 2000. Adaptation to Drifting User's Intersects, ECML2000/MLnet workshop: ML in the New Information Age. Barcelona, Spain 39-45.

LUBEGA, J. and WILLIAMS, S. 2006. A Study of Factors Contributing to Late Submission of Course Work, European Journal of Open, Distance and E-learning (EURODL), 2.

LUBEGA, J., SUN, L. and WILLIAMS, S. 2005. A Design for Generating Personalised Feedback in Knowledge Construction. Springer-Verlag, Berlin Heidelberg, 302-310.

LUBEGA, J., SUN, L. and WILLIAMS, S. A. 2005. A Method for Personalised Tracking in Knowledge Construction. In Proceedings of the $4^{\text {th }}$ European Conference on $e$ Learning (ECEL), Amsterdam, The Netherlands. 
LUBEGA, J. and WILLIAMS, S. 2004. Patterns of Use when Interacting with a Managed Learning Environment. In the proceedings of the 16th World Conference on Educational Multimedia, Hypermedia \& Telecommunications, Lugano, Switzerland.

MORY E.H. 2003. Feedback research revisited, in D.H. Jonassen (Ed.), Handbook of research for educational communications and technology. New York: MacMillian Library.

PAIVA, A. and MACHADO, I. 2002. Lifelong Training with Vincent, a Web-based Pedagogical Agent. International Journal of Continuing Engineering Education and Lifelong Learning, 12 (1-4), 254-256.

ROWNTREE, D. 1987. Assessing Students: How Shall We Know Them, Kogan Page, London.

SCORM, 2005. Best Practices Guide for Content Developers. Learning Systems Architecture Lab. Retrieved September 09, 2006 from: http://www.lsal.cmu.edu/lsal/expertise/projects/

STEFFE, L.P., \& GALE, J. 1995. Constructivism in Education. Hillsdale, NJ: Erlbaum. Stiggins, R. (2002). Assessment Crisis: The Absence of Assessment FOR Learning, Phi Delta Kappan, 83, 758-765.

SUN, L. and FU, Y. 2005. Interoperability for eLearning Services Management and Provision, Journal of World Wide Web: Internet and Web Information Systems, 8, 1-18.

SUN, L. and WILLIAMS, S. 2004. An Instructional Design Model for Constructivist Learning. Conference Proceedings, EdMedia 2004 World Conference on Multimedia, Hypermedia and Telecommunication, Lugano, Switzerland, 2476-2483.

SUN, L., OUSMANOU, K. and WILLIAMS, S A. (2004). Articulation of Learners Requirements for Personalised Instructional Design in E-Learning Services. In Liu, W., Shi, Y. and Li, Q. (Eds.), Advances in Web-based Learning: Lecture Notes in Computer Science, Berlin Heidelberg: Springer-Verlag, 3143, 424-431.

TORRANCE, H. and PRYOR, J. (1998). Investigating Formative Assessment, Open University Press, Buckingham.

WIGGINS, G. 1998. Educative assessment: Designing assessments to inform and improve student performance, Jossey-Bass, San Francisco.

WILEY, D. A. 2000. Connecting learning objects to instructional design theory: A definition, a metaphor, and a taxonomy. In Wiley, D. A. (ed., The Instructional Use of Learning Objects, Retrieved June 23, 2006 from:

http://reusability.org/read/chapters/wiley.doc 